\title{
Treatment of Comorbid Anxiety and Depression with Escitalopram: Results of a Post-Marketing Surveillance Study
}

\author{
Authors \\ G. Laux ${ }^{1}$ M. Friede ${ }^{2}$, W. E. Müller ${ }^{3}$ \\ Affiliations \\ ${ }^{1}$ kbo-Inn-Salzach-Klinikum gGmbH, Wasserburg a. Inn, Germany \\ ${ }^{2}$ Lundbeck GmbH, Hamburg, Germany \\ ${ }^{3}$ Department of Pharmacology, University of Frankfurt, Frankfurt, Germany
}

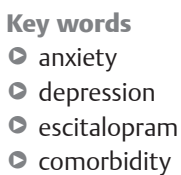

Bibliography

DOI http://dx.doi.org/

$10.1055 / \mathrm{s}-0032-1311627$

Published online ahead of print: 30 May 2012

Pharmacopsychiatry 2013;

46: $16-22$

(c) Georg Thieme Verlag KG Stuttgart · New York

ISSN 0176-3679

Correspondence

\section{Prof. Dr. G. Laux}

kbo-Inn-Salzach-Klinikum gGmbH

Fachkrankenhaus für

Psychiatrie, Psychotherapie,

Psychosomatische Medizin und

Neurologie

Gabersee 7

83512 Wasserburg

Germany

Tel.: +49/8071/71 215

Fax: $+49 / 8071 / 71318$

g.laux-isk@t-online.de

\section{Abstract}

$\nabla$

Introduction: In this 16-week post-marketing surveillance (PMS) study, antidepressant effects and tolerability of escitalopram was examined in 2911 patients with comorbid depression and anxiety.

Methods: Antidepressant effects were assessed using a modified version of the MontgomeryÅsberg depression rating scale (svMADRS), the Hamilton anxiety scale (HAMA) and the hospital anxiety depression scale (HADS-D) and the clinical global impression scale (CGI-S, CGI-I).

Results: Treatment was completed by 2718 patients, whose severity of depression decreased from a mean svMADRS total score of 33.0 to 8.9.

\section{Introduction}

$\nabla$

Selective serotonin reuptake inhibitors (SSRI) like escitalopram are mainly used for drug treatment of depression and anxiety disorders. For escitalopram like for many other SSRI's efficacy data for major depression (MDP) and most anxiety disorders are available. Due to their good efficacy and tolerability, they have largely replaced tricyclic antidepressants [1,2]. Differences between individual SSRIs with regard to effectiveness and adverse effect profile mainly occur due to pharmacokinetic factors and different affinities for the serotonin transporter.

In order to provide scientific evidence of efficacy in controlled randomised clinical studies (RTC's), only patients with one disorder are usually included. However, comorbid anxiety disorders and depression occur frequently in daily practice. Especially generalised anxiety disorder (GAD) rarely occurs alone: $90 \%$ of patients with GAD also report other psychiatric disorders in their medical history; in two-thirds of the cases, they also suffer from depression [3]. Inversely, it is
At the end of the study, the remission rate (svMADRS $\leq 12$ ) was $72.9 \%$ and the response rate ( $\geq 50 \%$ decrease in svMADRS score) was $83.1 \%$ (LOCF). Similarly, the severity of anxiety symptoms decreased from a mean HAMA total score of 28.8-8.8; the remission rate $($ HAMA $<10)$ was $63.9 \%$ and the response rate (decrease $\geq 50 \%$ ) was $80.2 \%$. The most frequent adverse events were nausea (1.6\%), agitation (1.1\%) and fatigue (0.7\%).

Discussion: Antidepressant effects and good tolerability of escitalopram were confirmed in everyday practice in patients with comorbid depression and anxiety. The high response and remission rates were within the range reported in previous RTC's of escitalopram vs. comparators or vs. placebo.

also estimated that $20-30 \%$ of the patients with major depression also suffer from GAD [4]. The results of a prospective, longitudinal cohort study in New Zealand [5] even showed somewhat higher values: $48 \%$ of the patients with depression also suffered from anxiety disorders at some point in time in their lives and, inversely, $72 \%$ of the patients with GAD also had a history of depression. Altogether, $12 \%$ of the 1037 persons examined were comorbid with depression and anxiety disorder. The authors concluded that the proportion of the population suffering from comorbid depression and anxiety disorder is larger than usually assumed.

A summary of methodical requirements on controlled, randomised double-blind studies on the treatment of anxiety disorders can be found in Broich [6].

Within the scope of a post-marketing surveillance (PMS) study, the practically relevant, naturalistic use of a drug can be better evaluated than in a typical RTC. Thus, the present study examines the usefulness and tolerability of escitalo- 
pram under routine conditions in Germany in outpatients with comorbid anxiety and depression.

\section{Patients and Methods}

\section{Patients}

The data in this multicentre study were collected from November 2005 until December 2006 in Germany. A total of 994 registered physicians of different specialties (general physicians, practical physicians, internists and specialists for psychiatry) treated 2911 patients with escitalopram over a period of 16 weeks. The participating patients were outpatients and at least 18 years old. Patients were comorbid and suffered from depression and anxiety. In this context, comorbidity of depression and anxiety was defined as a combination of the diagnosis "depression" on the basis of ICD-10 classification F32 or F33 and a baseline sVMADRS > 12 with the diagnosis "anxiety" on the basis of ICD-10 classification F40 or F41 and a baseline HAMA $\geq 10$. Patients were not treatment resistant defined as showing no response to 2 previous different antidepressants in sufficient dosing over a period of at least 2 weeks. Patients with known intolerability to escitalopram or citalopram or a contraindication for treatment with escitalopram were not included. Patients were not permitted to simultaneously participate in other studies.

\section{Study design}

Patients were treated (tablets or drops) for 16 weeks. The dose was decided by the attending physician. During this period, 4 examinations were performed within the scope of the study: 1 examination at the time of the inclusion into the study (week 0 ), 2 follow-up examinations (week 2 and week 8 ) and 1 final examination (week 16). During the inclusion examination, the following data were collected: demographics, height, weight, diagnosis, psychotropic pre-treatment, concomitant diseases and medication, and medical history.

This study did not influence physicians' individual decision concerning diagnosis, dosing, or course of treatment.

\section{Assessments}

In order to determine the therapeutic effect of escitalopram, validated and established scales were used in this study. Quality of the recorded data was assured by double data entry and analysis by a clinical research organisation (CRO). Physicians were familiar with the used scales or they had the possibility to train the use of the rating scales to assure a good data quality.

Severity of disease was assessed using the Clinical Global Impression of Severity Scale (CGI-S), change in condition was assessed using the Clinical Global Impression of Improvement Scale (CGI-I) [7]. The CGI-I is a 7 point-scale ranging from "condition is much worse" (7 points) to "condition is much better" $(\mathrm{CGI}-\mathrm{I}=2)$ and "condition is very much better" (CGI-I=1). Patients who described their condition to be "much better" or "very much better" after treatment were considered to be responders.

Severity of anxiety or depression was measured using the German versions of established third-party (clinician) rating scales, the Hamilton Anxiety Scale (HAMA) [7] and the MontgomeryÅsberg Depression Rating Scale (MADRS) [8], which comprises 10 items assessed by the physician from 0 to 6 , giving a maximum of 60 points. The svMADRS (sv=short version) is a modified version in which anchor points are not used and the symptoms are not defined but only mentioned. For the original version of the MADRS, a score $\geq 30$ points usually corresponds to severe depression, a score between 13 and 21 to mild depression in individual cases, and a score $\leq 12$ to remission.

The maximum HAMA total score is 56; patients with a mild anxiety disorder have a score of 10 or less, and patients with generalised anxiety disorder (GAD) have a score of 20 or more [9]. The German version of the Hospital Anxiety Depression Scale (HADS-D) [7] was used for self-assessment of anxiety and depression symptoms by the patients. This questionnaire consists of 14 items including 7 items referring to depression (HADS-D "depression") and 7 items referring to anxiety (HADSD “anxiety"). Both HADS-D scales have a score range of 0-21.

The dosage of escitalopram was individually determined by the attending physician after the initial visit. Escitalopram could be used as coated tablets $10 \mathrm{mg}$ and $20 \mathrm{mg}$ and escitalopram $10 \mathrm{mg} /$ $\mathrm{mL}$ solution. Depending on the patient response to treatment, the dosage adaptation was allowed at any time during the study. The primary endpoints included remission using the svMADRS (total score $\leq 12$ ) and HAMA scale (HAMA $\leq 10)$. Secondary endpoints included the time course of changes in symptom severity and responder rates ( $\geq 50 \%$ decrease from baseline in svMADRS and HAMA scores; CGI-I of 1 or 2 = "very much better" or "much better"). At the end of the observation period, patients and physicians separately evaluated efficiency and tolerability ranging from "insufficient", to "moderate", "good", and "very good". All unexpected events were considered "adverse events", even if they did not have any apparent causal relationship with treatment. This included the deterioration of an existing condition, but not lack of therapeutic effect. Serious adverse events were defined as symptoms that led to death or permanent disability, were life-threatening, required or extended a hospital stay, and to congenital anomalies or birth defects. Events which required medical intervention in order to prevent one of the above mentioned criteria were classified as severe and adverse.

During every follow-up examination and at final examination patients were asked for adverse events. In the case of a serious adverse event it had to be sent within $24 \mathrm{~h}$ to the selected CRO responsible for collecting and handling of all adverse events in this post-marketing surveillance study.

\section{Statistical analyses}

This post-marketing surveillance study was evaluated using methods of descriptive statistics using last-observation-carriedforward (LOCF) analysis. Multiple linear regression and covariance analytical models were used to analyse the dose groups ( $10 \mathrm{mg} /$ day and $20 \mathrm{mg} /$ day) for continuous parameters; logistic regressions were used to compare the dose groups ( $10 \mathrm{mg} /$ day and $20 \mathrm{mg} /$ day) regarding binary parameters (e.g., remission rates). Categorical data were analysed using the chi-square test. Linear regression, using stepwise backward elimination $(p>0.15)$, was used to model change from baseline to week 16 on the SVMADRS, HAMA and HADS-D. The following factors were tested: age, sex, BMI, mono-diagnosis of depression or anxiety, classification by diagnostic group, somatic disorders, other psychiatric disorders, total duration of illness, duration of current episode, pre-treatment of current episode, marital status, concomitant diseases, baseline scores on the sVMADRS, HAMA and CGI-S, and escitalopram dose.

The Statistical Software Package SAS ${ }^{\circledR}$ was used for the formal statistical analyses. 


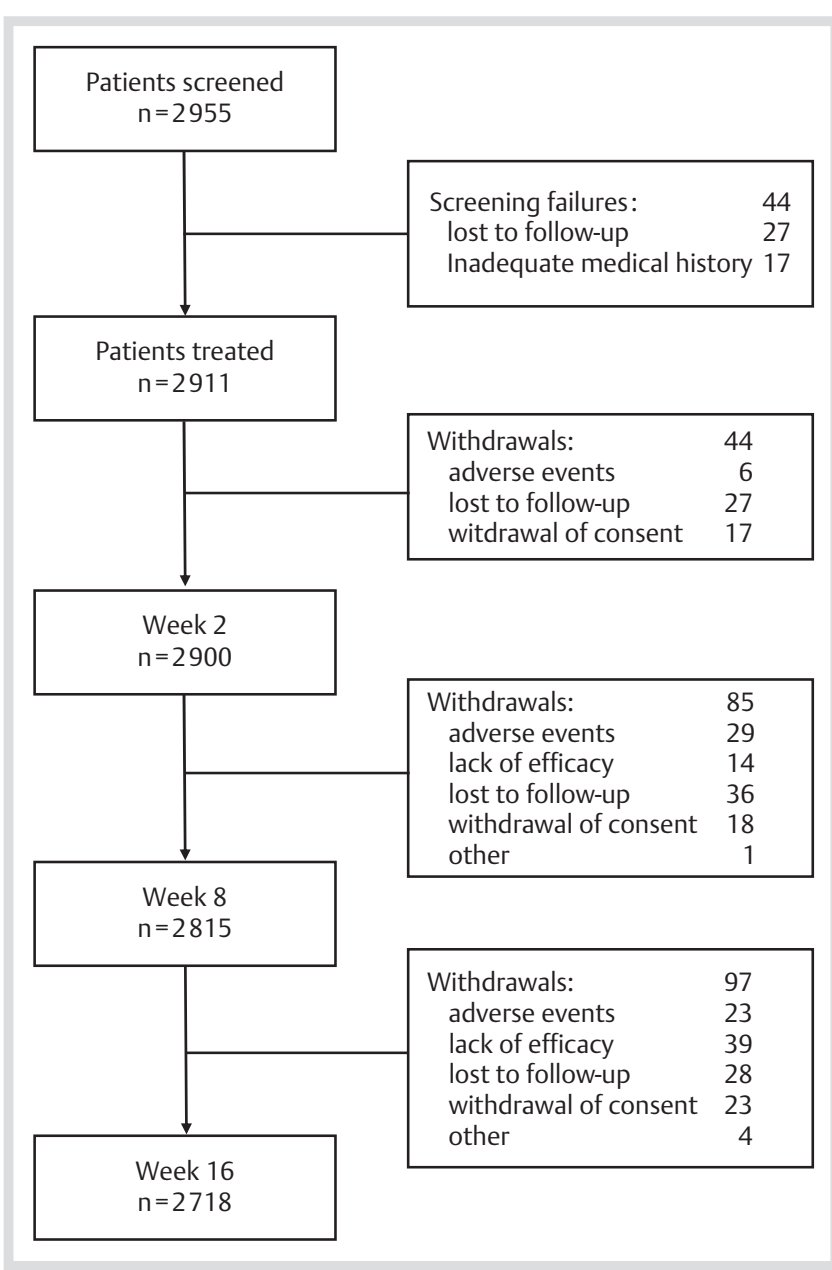

Fig. 1 Patient flow and reasons for withdrawal during the treatment period.

\section{Results}

$\nabla$

\section{Demographic data}

Altogether, 2911 patients treated with escitalopram were included in the study, comprising the all-patient-treated set (APTS) or safety population. Two-thirds (68.0\%) of the patients were women, with a mean weight of $69.8 \pm 12.4 \mathrm{~kg}$ and a mean height of $167 \pm 6 \mathrm{~cm}$. Male patients had a mean weight of $82.1 \pm 11.6 \mathrm{~kg}$ and a mean height of $178 \pm 6 \mathrm{~cm}$. There were 193 patients who prematurely withdrew from the study; thus 2718 patients $(93.4 \%)$ of the APTS completed 16-weeks treatment (० Fig. 1).

There were 2185 patients who met the inclusion criteria: comorbidity in the sense of an ICD-10 diagnostic classification of F32/ F33 plus F41/F40, a baseline svMADRS $>12$ and a baseline $H A M A \geq 10$, as well as documented assessments during the study. This group of patients was designated as the "full-analysis set" (FAS) and was evaluated separately. Early study withdrawal occurred for 109 patients, resulting in a completion rate of $95.0 \%$.

The APTS ( $\mathrm{n}=2911$ ) could be divided into 4 diagnostic groups: comorbid depression and anxiety disorder $(n=2371$ : $81.4 \%$ ), exclusively depression ( $\mathrm{n}=284: 9.8 \%)$, exclusively anxiety $(\mathrm{n}=188: 6.5 \%)$ and other diagnoses $(\mathrm{n}=68: 2.3 \%) . \odot$ Table 1 provides an overview of the demographic data of the patients at baseline. The median age at the first depressive episode was 35
Table 1 Demographic and clinical data (FAS, $n=2185)$.

\begin{tabular}{|ll}
\hline Parameter & Mean \\
\hline age \pm SD & $47.3 \pm 14.1$ years \\
\hline - $\leq 30$ years & $12.9 \%$ \\
\hline - 31-40 years & $20.5 \%$ \\
\hline - $41-50$ years & $25.6 \%$ \\
- 51-65 years & $31.4 \%$ \\
\hline - >65 years & $9.7 \%$ \\
\hline BMI \pm SD* & $25.3 \pm 4.1 \mathrm{~kg} / \mathrm{m}^{2}$ \\
\hline single* & $30.2 \%$ \\
\hline clinical assessments \pm SD & \\
\hline - sVMADRS & $33.8 \pm 8.9$ \\
\hline - HAMA & $29.5 \pm 8.5$ \\
\hline - HADS-D & $30.1 \pm 6.1$ \\
\hline - CGI-S & $5.02 \pm 0.74$ \\
\hline
\end{tabular}

*Based on the APTS ( $n=2911$ ); CGI-S: Clinical Global Impression of Severity scale, HADS-D: Hospital Anxiety and Depression Scale - German version, HAMA: Hamilton Anxiety Scale (assessment of the severity of anxiety), svMADRS: MontgomeryÅsberg Depression Rating Scale - short version, FAS: Full-Analysis Set

years, and the median length of the disease was 10 years. The severity of previous episodes was predominantly moderate. The median age at first occurrence of an anxiety disorder was 38 years, with a median length of disease of 6 years. Treatment of previous depression or anxiety conditions was reported by $55.8 \%$ of the patients. The median length of the current episode was 6 weeks, for which $35.7 \%$ of the patients had received treatment. In addition, $39.5 \%$ of the patients of the comorbid group suffered from a somatic syndrome, and $11.1 \%$ from an additional mental disorder.

\section{Medication}

Prior to initiation of treatment with escitalopram, $35.7 \%$ of patients had been treated with at least one of the following: tri- or tetracyclic antidepressants $(n=385)$, SSRIs $(n=250)$, noradrenergic and specific serotonergic antidepressants $(n=183)$, serotonin and noradrenergic reuptake inhibitors $(n=90)$, phytotherapeutic antidepressants $(n=82)$, noradrenergic antidepressants $(n=13)$, monoamine oxidase inhibitors ( $n=9)$, or psychotherapy $(n=6)$. For 23 patients, the treatment was not recorded, and 259 patients were treated with other medications.

At the beginning of the study, $70.4 \%$ of patients $(n=2049)$ were treated with $10 \mathrm{mg} /$ day escitalopram, $21.5 \%(\mathrm{n}=626)$ received $20 \mathrm{mg} /$ day, and $7.0 \%(\mathrm{n}=203)$ received $5 \mathrm{mg} /$ day (APTS). Only 3 patients took more than $20 \mathrm{mg} /$ day, 12 patients took $15 \mathrm{mg} /$ day, and the remaining patients $(\mathrm{n}=18)$ took less than $10 \mathrm{mg} /$ day. By the end of the study, the dose had been changed at least once: for 1355 of the 2270 patients in the $10 \mathrm{mg}$ group (59.7\%) and for 171 of the 641 patients in the $20 \mathrm{mg}$ group (26.7\%) (APTS). For the FAS, 1687 patients were initially treated with $10 \mathrm{mg} /$ day and 498 received $20 \mathrm{mg}$ /day escitalopram.

For 2546 patients ( $87.5 \%$, APTS), escitalopram was subsequently used for maintenance treatment, with $48.8 \%$ of the patients being treated with $10 \mathrm{mg} / \mathrm{day}(\mathrm{n}=1242)$ and $43.3 \%$ with $20 \mathrm{mg} /$ day $(\mathrm{n}=1103)$. A few patients continued maintenance therapy on $5 \mathrm{mg}(\mathrm{n}=68), 15 \mathrm{mg}(\mathrm{n}=72), 30 \mathrm{mg}(\mathrm{n}=42)$, or $40 \mathrm{mg}$ escitalopram $(n=13)$. At the end of the study, $9.6 \%$ of patients $(n=277)$ did not continue treatment, $85.8 \%$ of patients $(n=2473)$ continued with escitalopram alone, $2.5 \%$ of patients $(n=73)$ combined escitalopram with another antidepressant, and $1.4 \%$ of patients $(\mathrm{n}=40)$ switched to another antidepressant (APTS). 
Table 2 Difference in total scores between inclusion and after 16 weeks, remission and response rates [\%] (FAS, LOCF).

\begin{tabular}{|c|c|c|c|c|}
\hline & SVMADRS & HAMA & HADS-D & CGI-I \\
\hline change in total score & $-25.5 \pm 10.8$ & $-21.2 \pm 9.3$ & $-20.1 \pm 8.9$ & $-1.57 \pm 0.75^{\ddagger}$ \\
\hline response rate & $86.7 \%$ & $83.8 \%$ & - & $92.0 \%$ \\
\hline remission rate & $76.0 \%$ & $66.3 \%$ & $57.7 \%$ & - \\
\hline
\end{tabular}

\section{Severity of depression (svMADRS)}

At the beginning of the study, severe depression (svMADRS $\geq 29$ ) was diagnosed in $70.8 \%$ of the patients with comorbid depression, moderate depression in $20.0 \%$ of patients (svMADRS $22-28$ ), and mild depression (svMADRS $\geq 21$ ) in $9.2 \%$ of patients (FAS). During the course of this 16-week surveillance study, the mean baseline sVMADRS of $33.8 \pm 8.9$, decreased to $24.5 \pm 10.0$ at week $2,13.5 \pm 8.9$ at week 8 , and $8.2 \pm 7.8$ at week 16 , corresponding to a mean improvement of $25.5 \pm 10.8$ ( $\odot$ Table 2, FAS, LOCF). The response rate was $16.9 \%$ at week $2,67.5 \%$ at week 8 , and $86.7 \%$ at week 16 ; and the remission rate was $11.6 \%$ at week 2 , $51.4 \%$ at week 8 , and $76.0 \%$ at week 16 (FAS, LOCF). For patients treated with $10 \mathrm{mg}$ escitalopram $(\mathrm{n}=1687)$, the mean baseline svMADRS was $33.2 \pm 8.8$, decreasing to $24.5 \pm 10.0$ at week 2 , $13.5 \pm 8.8$ at week 8 , and $8.2 \pm 7.8$ at week 16 , corresponding to a mean improvement of $25.0 \pm 10.6$ (FAS, LOCF). For patients treated with $20 \mathrm{mg}$ escitalopram $(\mathrm{n}=498)$, the mean baseline svMADRS was $35.5 \pm 9.1$, decreasing to $24.9 \pm 10.1$ at week 2 , $13.7 \pm 9.2$ at week 8 , and $8.3 \pm 7.9$ at week 16 , corresponding to a mean improvement of $27.1 \pm 11.0$ (FAS, LOCF).

For the safety population (APTS), the severity of depression decreased from a mean svMADRS total score of $33.0 \pm 9.4$ to $8.9 \pm 8.7$, corresponding to a mean difference of $-24.0 \pm 11.6$ (APTS, LOCF). The corresponding response rate ( $\geq 50 \%$ improvement from baseline in the svMADRS score) was $83.1 \%$ and the remission rate (svMADRS $\leq 12$ ) was $72.9 \%$ (LOCF).

\section{Severity of anxiety (HAMA)}

At the beginning of the study, $99.3 \%$ of patients had a HAMA $>10$. For patients with comorbid depression, the mean baseline HAMA was $29.5 \pm 8.5$, decreasing to $8.3 \pm 7.2$, corresponding to a mean difference of $21.2 \pm 9.3$ (FAS, LOCF). For patients with comorbid depression, the response rate was $15.0 \%$ at week $2,63.5 \%$ at week 8 , and $83.8 \%$ at week 16 ; the corresponding remission rates were $7.9 \%$ at week 2, 38.8\% at week 8 and $66.3 \%$ at week 16 ( $\odot$ Table 2, FAS, LOCF).

For the safety population (APTS), the severity of anxiety decreased from a mean HAMA total score of $28.8 \pm 8.6$ to $8.8 \pm 7.9$, corresponding to a mean improvement of $20.0 \pm 10.0$ (LOCF). The response rate $(\geq 50 \%$ improvement from the baseline HAMA total score) was $80.2 \%$, and the remission rate $($ HAMA $<10)$ was $63.9 \%$ (LOCF).

\section{Self-assessment of anxiety and depression (HADS-D)}

At the beginning of the study, $99.6 \%$ of patients had self-assessment total scores $>10$. For patients with comorbid depression, the mean baseline HADS-D score was $30.1 \pm 6.1$, decreasing to $10.0 \pm 7.1$, corresponding to a mean improvement of $20.1 \pm 8.9$ (FAS, LOCF). For patients with comorbid depression, remission was achieved by $3.2 \%$ of patients at week $2,28.2 \%$ at week 8 , and $57.7 \%$ at week 16 (FAS, LOCF). For the safety population (APTS), the total mean HADS-D score decreased from $29.6 \pm 6.4$ to
Table 3 Difference in the mean total scores between the beginning and the end of the study in the dose groups $10 \mathrm{mg} /$ day and $20 \mathrm{mg} /$ day (FAS, LOCF).

\begin{tabular}{|c|c|c|}
\hline & $\begin{array}{l}\text { Escitalopram } 10 \mathrm{mg} / \text { day } \\
(\mathrm{n}=1687)\end{array}$ & $\begin{array}{l}\text { Escitalopram } 20 \mathrm{mg} / \text { day } \\
(\mathrm{n}=498)\end{array}$ \\
\hline svMADRS & $-25.0 \pm 10.6$ & $-27.1 \pm 11.0^{*}$ \\
\hline HAMA & $-20.8 \pm 9.2$ & $-22.7 \pm 9.7^{* *}$ \\
\hline HADS-D & $-19.6 \pm 8.7$ & $-21.8 \pm 9.2^{* * *}$ \\
\hline CGI-S & $-2.50 \pm 1.21$ & $2.69 \pm 1.25^{\ddagger}$ \\
\hline $\begin{array}{l}\text { *svMADRS: } \\
\text { **HAMA: } \\
\text { ***HADS- } \\
\text { CGI-S: Clini } \\
\text { Hospital An } \\
\text { Scale (asses } \\
\text { svMADRS: }\end{array}$ & $\begin{array}{l}0033 \\
011 \\
.0001, \text { CGI-S: } p=0.0157,20 \mathrm{~m} \\
\text { bal Impression of Severity scal } \\
\text { and Depression Scale - Germar } \\
\text { t of the severity of anxiety), LO } \\
\text { omery-Åsberg Depression Rati }\end{array}$ & $\begin{array}{l}10 \mathrm{mg} \\
\text { ADS-D: FAS: full analysis set, } \\
\text { sion, HAMA: Hamilton Anxiety } \\
\text { ast observation carried forward, } \\
\text { cale - short version }\end{array}$ \\
\hline
\end{tabular}

$10.7 \pm 7.8$, corresponding to a mean improvement of $18.9 \pm 9.5$ (LOCF). The remission rate was $55.2 \%$ after 16 weeks (HADS$\mathrm{D} \leq 10)(\mathrm{LOCF})$.

\section{Severity and change in condition (CGI-S, CGI-I)}

The CGI-S score decreased from $4.97 \pm 0.76$ to $2.57 \pm 1.17$, corresponding to a mean difference of $2.41 \pm 1.30$ (APTS, LOCF). For patients with comorbid depression, the CGI-S score was $5.02 \pm 0.74$ at the beginning of the study, $4.30 \pm 0.97$ at 2 weeks, $3.18 \pm 1.06$ at 8 weeks and $2.48 \pm 1.11$ at the final examination, corresponding to a mean difference to baseline of $2.54 \pm 1.22$ (FAS, LOCF). The mean CGI-I scores were $2.84 \pm 0.83$ at week $2,1.95 \pm 0.75$ at week 8 and $1.57 \pm 0.75$ at the end of the study. At the first follow-up examination (week 2), 31.8\% of patients could be classified as responders $(\mathrm{CGI}-\mathrm{I} \leq 2)$ (FAS). After 8 weeks, $82.1 \%$ of patients were responders, increasing to $92.0 \%$ at 16 weeks (FAS, LOCF). The response rates at 16 weeks were not significantly different $(\mathrm{p}=0.5234)$ for patients taking $10 \mathrm{mg} /$ day (92.2\%) and $20 \mathrm{mg} /$ day (91.3\%).

\section{Dosage}

Patients treated with $20 \mathrm{mg} /$ day $(\mathrm{n}=498)$ had significantly higher mean total scores (svMADRS, HAMA, HADS-D) at baseline than patients treated with $10 \mathrm{mg} /$ day $(\mathrm{n}=1687)$ - svMADRS: $35.5 \pm 9.1$ vs. $33.2 \pm 8.8$, HAMA: $31.0 \pm 8.7$ vs. $29.1 \pm 8.3$, HADS-D: $31.5 \pm 5.7$ vs. $29.7 \pm 6.1$, respectively $(\mathrm{p}<0.0001$ for all). For patients whose dosage was fixed at $20 \mathrm{mg} /$ day escitalopram at the beginning of the study, the decrease in the mean total scores was greater than for patients treated with $10 \mathrm{mg} /$ day ( $\odot$ Table 3 ), even after adjustment for baseline scores.

\section{Factors}

Higher baseline levels of the svMADRS, HAMA and CGI-S scales and a higher escitalopram dose were significantly correlated with a greater decrease in the mean total scores from baseline. Three factors with a significantly unfavourable influence on the decrease in the mean total scores from baseline were the pres- 
Table 4 Adverse events with at least a possible relationship with escitalopram.

\begin{tabular}{|lccc|}
$\begin{array}{l}\text { Preferred } \\
\text { term }\end{array}$ & $\begin{array}{c}\text { Escitalopram } \\
\mathbf{1 0} \mathbf{m g} / \text { day } \\
(\mathbf{n = 2 2 7 0 )}\end{array}$ & $\begin{array}{c}\text { Escitalopram } \\
\mathbf{2 0} \mathbf{m g} / \text { day } \\
\mathbf{( n = 6 4 1 )}\end{array}$ & $\begin{array}{c}\text { APTS } \\
\text { (n=2911) }\end{array}$ \\
\hline nausea & $43(1.89 \%)$ & $3(0.47 \%)$ & $46(1.58 \%)$ \\
\hline agitation & $31(1.37 \%)$ & $1(0.16 \%)$ & $32(1.10 \%)$ \\
\hline diarrhoea & $15(0.66 \%)$ & $2(0.31 \%)$ & $17(0.58 \%)$ \\
\hline hyperhidrosis & $16(0.70 \%)$ & - & $16(0.55 \%)$ \\
\hline dizziness & $15(0.66 \%)$ & - & $15(0.52 \%)$ \\
\hline fatigue & $12(0.53 \%)$ & $1(0.16 \%)$ & $13(0.45 \%)$ \\
\hline weight gain & $7(0.31 \%)$ & $1(0.16 \%)$ & $8(0.27 \%)$ \\
\hline vomiting & $7(0.31 \%)$ & $1(0.16 \%)$ & $8(0.27 \%)$ \\
\hline sleep disorder & $7(0.31 \%)$ & - & $7(0.24 \%)$ \\
\hline anxiety & $7(0.31 \%)$ & - & $7(0.24 \%)$ \\
\hline palpitations & $6(0.26 \%)$ & - & $6(0.21 \%)$ \\
\hline loss of libido & $4(0.18 \%)$ & $2(0.31 \%)$ & $6(0.21 \%)$ \\
\hline
\end{tabular}

ence of other psychiatric disorders or pre-treatment of the current episode. Age, total disease duration, and duration of the current episode also had a negative effect on treatment outcome, but to a lesser degree. Sex, BMI, mono-diagnosis of anxiety or depression, somatic symptoms, and classification by diagnostic group (ICD-10) were without significant influence on outcome.

\section{Adverse events}

In the course of the study, 346 adverse events were reported by 189 patients (6.5\%) (APTS). In 157 (5.4\%) instances, a causal relationship with escitalopram was at least considered possible. A significantly higher incidence of adverse events was reported in the group of patients who were stabilised on $10 \mathrm{mg} /$ day escitalopram in the beginning. In this group, 171 out of 2270 patients (7.5\%) reported adverse events, compared to 18 out of 641 patients $(2.8 \%)$ in the group that started treatment on $20 \mathrm{mg} / \mathrm{day}$ escitalopram in the beginning $(\mathrm{p}<0.0001)$. The adverse event was not considered to be severe in 172 of the 189 cases. In 58 cases, escitalopram was stopped due to adverse events. Adverse events with at least a possible relationship with escitalopram are shown in $\odot$ Table 4.

\section{Severe adverse events}

17 patients reported 19 severe adverse events. 2 patients attempted suicide, with suicidal thoughts registered in one case, and acute suicidal tendency in another case. A causal relationship with medication was evaluated as "possible" in 2 cases (suicidal thoughts, one attempted suicide). The other severe adverse events were deterioration of condition ( 3 cases), lack of effect ( 3 cases), hospitalisation ( 2 cases), and one case of renal cell carcinoma, myocardial infarction with ST-segment elevation, abnormal gynaecological examination, alcohol abuse, agitation and anxiety, and continuous vaginal bleeding. No deaths were reported in the course of the study. Concerning the cardiac adverse events no cases of QTc-prolongation were reported.

\section{Therapeutic effect and tolerability of escitalopram}

Therapeutic effects and tolerability were described as "good" or "very good" by most physicians and patients. In the APTS $(n=2911), 92.2 \%$ of physicians and $89.6 \%$ of patients assessed the therapeutic effects of escitalopram to be "good" or "very good", whereas $2.5 \%$ of physicians and $3.8 \%$ of patients described it "insufficient".
For the full analysis set ( $\mathrm{n}=2185$ ), $94.8 \%$ of physicians and $92.6 \%$ of patients described the therapeutic effects as "good" or "very good", compared to $1.2 \%$ of physicians and $1.8 \%$ of patients with "insufficient". Most physicians (97.4\%) and patients (96.1\%) evaluated tolerability as "good" or "very good", and $0.9 \%$ of physicians and $1.5 \%$ of patients considered the tolerability of escitalopram "insufficient". At the end of the study, $87.5 \%$ of the patients continued maintenance treatment with escitalopram.

\section{Discussion}

$\nabla$

The therapeutic efficacy of escitalopram in patients with depression or different anxiety disorders was demonstrated in several placebo-controlled, randomised and blind clinical studies [1014]. Significant improvements of anxiety symptoms in depressive patients could also be shown by means of pooled data from double-blind placebo-controlled studies $[15,16]$.

The present PMS examined under relevant conditions of daily practice and by means of standardised methods, the use of escitalopram in patients with both indications, i.e., depression and anxiety disorder, a combination which is common in daily clinical practice. In this context, the therapeutic usefulness and good tolerability of escitalopram, which was already known from controlled clinical studies, including patients with comorbid depression and anxiety [17], was confirmed.

In the group of patients who were stabilised on $20 \mathrm{mg} /$ day escitalopram at the beginning of the study, the decrease in the mean total scores (svMADRS, HAMA, HADS-D) was clearer in the course of the study than in the group treated with $10 \mathrm{mg} /$ day in the beginning. The difference could only be partially explained by the higher level of total scores in the $20 \mathrm{mg}$ group at the beginning of the study. Even after adjustment for baseline severity, a significantly clearer decrease in the total scores on all 3 scales was shown with initial treatment with $20 \mathrm{mg} /$ day.

The adverse events spectrum was similar to that reported in controlled clinical studies with escitalopram and citalopram; however, the incidence was slightly lower. Nausea was the dominant side effect in this study (1.6\% of patients), as in controlled studies in which the reported incidence was 6-17\% [9$11,13,14,18-20]$. A significant higher rate of adverse events was notable in the group of patients who were stabilised on the lower dose of $10 \mathrm{mg} /$ day escitalopram in the beginning. This result, which was surprising, might be attributed to the fact that patients who were treated with $20 \mathrm{mg} /$ day escitalopram perceived a greater improvement in their symptoms at week 2 (a decrease of 11.0 vs. 8.3 svMADRS points for $10 \mathrm{mg}$ ) and thus subjectively suffered less from the possible side effects at the beginning of the therapy.

The incidence of severe adverse events was $1.7 \%$. Attempted suicide was reported in 2 cases, and a relationship with escitalopram could not be excluded in one case. As the majority of the study participants suffered from severe depression and/or anxiety disorders, the occurrence of attempted suicide is not surprising [21].

The low incidence of cardiac adverse events ( $0.2 \%$ of patients) confirms the good tolerability of Escitalopram as shown in clinical practice.

Efficiency and tolerability of escitalopram were significantly higher in the group of patients with the higher initial dose of $20 \mathrm{mg} /$ day compared with the lower initial dose of $10 \mathrm{mg} /$ day. These results suggest to start treatment with $20 \mathrm{mg} /$ day for the 
Table 5 Response and remission rates from RCTs with Escitalopram (ESC) and the PMS study.

\begin{tabular}{|c|c|c|c|c|c|c|}
\hline \multirow[t]{2}{*}{ Study } & \multicolumn{2}{|c|}{ Response rate (\%) } & \multicolumn{4}{|c|}{ Remission rate (\%) } \\
\hline & ESC & CIT & PBO & ESC & CIT & PBO \\
\hline${ }^{1}$ PMS study** & $67.5 / 86.7$ & - & - & $51.4 / 76.0$ & - & - \\
\hline${ }^{2}$ Burke WJ et al. 2002 & $51.2^{\circ}$ & $45.6^{\circ}$ & 27.7 & - & - & - \\
\hline${ }^{3}$ Lepola UM et al. $2003^{*}$ & $63.7^{\circ \prime}$ & 52.6 & 48.2 & $52.1^{\prime}$ & 42.8 & no data \\
\hline${ }^{4}$ Colonna L et al. 2005 & $63.0^{\prime} / 80.0$ & $55.0 / 78.0$ & - & $55.0 / 76.0$ & $45.0 / 71.0$ & - \\
\hline${ }^{5}$ Moore N et al. 2005 & $76.1^{\prime \prime}$ & 61.5 & - & $56.1^{\prime}$ & 43.6 & - \\
\hline${ }^{6}$ Yevtushenko VY et al. 2007 & $95.4^{\prime \prime \prime}$ & 83.3 & - & $89.8^{\prime \prime \prime}$ & 50.9 & - \\
\hline
\end{tabular}

Response $=$ svMADRS $\geq 50 \%$ improvement from baseline, Remission $=$ svMADRS $\leq 12\left({ }^{1}\right.$ after $8 / 16$ weeks, ${ }^{2,3,5}$ after 8 weeks, ${ }^{4}$ after $8 / 24$ weeks, ${ }^{6}$ after 6 weeks) ITT, LOCF ( ${ }^{*} \mathrm{OC}$ analysis, ${ }^{* *}$ FAS), CIT: Citalopram, PMS: Post-Marketing Surveillance ${ }^{\circ} \mathrm{p}<0.01$ vs. $\mathrm{PBO}, \mathrm{p}<0.05$ vs. $\mathrm{CIT}$, " $\mathrm{p}<0.01$ vs. CIT, "'p<0.001 vs. CIT

acute therapy of patients with comorbid depression and anxiety disorder and to consider reducing the dose in the maintenance phase.

The present data are based on a post-marketing surveillance (PMS) study or non-interventional study (NIS). The methodology of PMS comprises series of intrinsic problems (e.g., interrater reliability, handling of missing data, comedication, heterogeneous patient population, inclusion and exclusion criteria). Moreover, PMS do not provide evidence of efficacy, but provide information on adverse events, dosage, medication adherence, and therapeutic effects indifferent group of patients usually not included in RTC's [12,22-24]. Response and remission rates in this PMS were rather high, which agrees with other PMS using escitalopram. In a naturalistic sample test among employed persons with affective and anxiety disorders, a clear reduction of the conditions was shown with escitalopram, together with an improvement of the severity of the disease according to CGI-S from 4.7 to 2.4 [25]. In another open, multicentric PMS, more than 11700 outpatients were treated with escitalopram over a period of 8 weeks. The response rate was $70 \%$, the remission rate $57 \%$ [26]. $83 \%$ of the patients described the efficiency as "good/very good", and $22 \%$ assessed the tolerability as "good/very good". On the other hand, these remission and response rates are within the range reported for escitalopram in RTC's vs. placebo or comparator in depression or anxiety (॰ Table 5).

Some of the latest controlled, double-blind studies provide response rates (under escitalopram) for depression between 63 and $70 \%$ and remission rates between 55 and 62\% [27-29]. Pooled results from double-blind placebo-controlled studies on the treatment of generalised anxiety disorders with escitalopram resulted in response rates of almost $48 \%$, and remission rates of $26 \%$ [30].

\section{Acknowledgements}

$\nabla$

The authors would like to thank Prof. Martin Härter (University Hospital of Freiburg, Germany) for his helpful comments on the present manuscript and methodological statistical advice relating to data analysis.

\section{Conflict of Interests}

The study was supported by Lundbeck GmbH, Karnapp 25, 21079 Hamburg. Dr. Laux has received research grants, and acted as consultant, advisor, or speaker for the following companies: Astra-
Zeneca, Bayer, Boehringer Ingelheim, Janssen-Cilag, Lilly, Lundbeck, Merz, Novartis, Organon, Pfizer, Servier, Steigerwald, Teva, Wyeth.

\section{References}

1 Gorman JM, Kent JM. SSRIs and SNRIs: broad spectrum of efficacy beyond major depression. J Clin Psychiatry 1999; 60 (Suppl 4): 33-38

2 Isaac $M$. Where are we going with SSRIs? Eur Neuropsychopharmacol 1999; 9 (Suppl 3): 101-106

3 Judd LL, Kessler RC, Paulus MP et al. Comorbidity as a fundamental feature of generalized anxiety disorders: results from the National Comorbidity Study (NCS). Acta Psychiatr Scand 1998; 393 (Suppl): 6-11

4 Pollack MH. Comorbid anxiety and depression. J Clin Psychiatry 2005; 66: 22-29

5 Moffitt TE, Harrington HL, Caspi A et al. Depression and generalized anxiety disorder. Cumulative and sequential comorbidity in a birth cohort followed prospectively to age 32 years. Arch Gen Psychiatry 2007; 64: 651-660

6 Broich K. Anforderungen an klinische Prüfungen mit Arzneimitteln bei Angststörungen. Psychopharmakotherapie 2006; 13: 241-247

7 CIPS. Internationale Skalen für Psychiatrie. Beltz Test GmbH, 2005

8 Möller HJ, Schnitker J. Einsatz einer modifizierten MADRS bei depressiven Patienten in einer prospektiven Kohortenstudie. Nervenarzt 2007; 78: 685-690

9 Allgulander C, Florea I, Huusom AKT. Prevention of relapse in generalized anxiety disorder by escitalopram treatment. Int J Neuropsychopharmacol 2005; 9: 1-11

10 Burke WJ, Gergel I, Bose A. Fixed-dose trial of the single isomer SSRI escitalopram in depressed outpatients. J Clin Psychiatry 2002; 63: 331-336

11 Davidson J, Bose A, Korotzer A et al. Escitalopram in the treatment of generalized anxiety disorder: Double-blind, placebo controlled, flexible dose study. Depress Anxiety 2004; 19: 234-240

12 Lepola UM, Loft H, Reines EH. Escitalopram (10-20 mg/day) is effective and well tolerated in a placebo-controlled study in depression on primary care. Int Clin Psychopharmacol 2003; 18: 211-217

13 Ninan PT, Ventura D, Wang J. Escitalopram is effective and well tolerated in the treatment of severe depression. Poster presented at the $156^{\text {th }}$ Annual Meeting of the American Psychiatric Association, San Francisco, USA, May 17-22, 2003

14 Wade AG, Lemming O, Hedegaard $K$. Escitalopram $10 \mathrm{mg} /$ day is effective and well-tolerated in a placebo-controlled study in depression in primary care. Int Clin Psychopharmacol 2002; 17: 95-102

15 Gorman JM, Korotzer A, Su G. Efficacy comparison of escitalopram and citalopram in the treatment of major depressive disorder: pooled analysis of placebo-controlled trials. CNS Spectrums 2002; 7: 40-44

16 Kennedy SH, Andersen HF, Thase ME. Escitalopram in the treatment of major depressive disorder: A meta-analysis. Curr Med Res Opin 2009; 25: 161-175

17 Boulenger $P$, Hermes A, Huusom AKT et al. Baseline anxiety effect on outcome of SSRI treatment in patients with severe depression: escitalopram vs paroxetine. Curr Med Res Opin 2010; 26: 605-614

18 Bielski RJ, Bose A, Chang CC. A double-blind comparison of escitalopram and paroxetine in the long-term treatment of generalized anxiety disorder. Ann Clin Psychiatry 2005; 17: 65-69

19 Kasper S, Stein D, Loft $H$ et al. Escitalopram in the treatment of social anxiety disorder. Randomised, placebo-controlled, flexible-dosage study. Br J Psychiatry 2005; 186: 222-226 
20 Rapaport M, Bose A, Zheng $H$ et al. Escitalopram prevents relapse of depressive episodes. Eur Psychiatry 2002; 17 (i): S97

21 Cipriani A, Barbui C, Geddes JR. Suicide, depression, and antidepressants. BMJ 2005; 330: 373-374

22 Laux G, Schüler P, Bruns S. Reboxetin in Klinik und Facharztpraxis. Psychopharmakotherapie 2000; 7: 162-167

23 Llorca PM, Azorin JM, Despiegel $N$ et al. Efficacy of escitalopram in patients with severe depression: a pooled analysis. Int J Clin Pract 2005; 59: 268-275

24 Yevtushenko VY, Belous AI, Yevtushenko YG et al. Efficacy and tolerability of escitalopram versus citalopram in major depressive disorder: A 6-week, multicenter, prospective, randomized, double-blind, active-controlled study in adult outpatients. J Clin Ther 2007; 29: 2319-2332

25 Winkler D, Pirek E, Klein $N$ et al. Escitalopram bei berufstätigen Menschen. Ergebnisse einer Anwendungsbeobachtung an 2378 Patienten. Psychopharmakotherapie 2006; 13: 142-146

26 Möller HJ, Friede M, Schmauß M. Behandlung der Depression mit Escitalopram. Ergebnisse einer großen Anwendungsbeobachtung. Psychopharmakotherapie 2007; 14: 149-156
27 Colonna L, Andersen HF, Reines EH. A randomized, double-blind, 24 -week study of escitalopram (10 mg/day) versus citalopram (20 mg/ day) in primary care patients with major depressive disorder. Curr Med Res Opin 2005; 21: 1659-1668

28 Montgomery SA, Huusom AKT, Bothmer J. A randomised study comparing escitalopram with venlafaxine XR in primary care patients with major depressive disorder. Neuropsychobiology 2004; 50: 57-64

29 Moore N, Verdoux H, Fantino B. Prospective, multicentre, randomized, double-blind study of the efficacy of escitalopram versus citalopram in outpatient treatment of major depressive disorder. Int Clin Psychopharmacol 2005; 20: 131-137

30 Goodman WK, Bose A, Wang Q. Treatment of generalized anxiety disorder with escitalopram: pooled results from double-blind, placebocontrolled trials. J Affect Dis 2005; 87: 161-167 